\title{
Clinicians' role in the occurrence of oral biopsy artifacts as a potential diagnostic dilemma
}

\section{Rola lekarzy klinicystów w powstawaniu artefaktów w badaniu histopatologicznym jamy ustnej jako możliwy dylemat diagnostyczny}

\author{
Massoumeh Zargaran ${ }^{A-F}$ \\ Department of Oral and Maxillofacial Pathology, Faculty of Dentistry, Kurdistan University of Medical Sciences, Sanandaj, Iran \\ A - research concept and design; $\mathrm{B}$ - collection and/or assembly of data; $\mathrm{C}$ - data analysis and interpretation; \\ $D$ - writing the article; $E$ - critical revision of the article; $F$ - final approval of the article
}

\section{Address for correspondence \\ Massoumeh Zargaran \\ E-mail: massoumehzargaran@gmail.com}

\section{Funding sources}

None declared

Conflict of interest

None declared

Received on February 11, 2019

Reviewed on March 11, 2019

Accepted on April 17, 2019

Published online on September 30, 2019

Cite as

Zargaran M. Clinicians' role in the occurrence of oral biopsy artifacts as a potential diagnostic dilemma. Dent Med Probl. 2019;56(3):299-306. doi:10.17219/dmp/108597

DOI

$10.17219 / \mathrm{dmp} / 108597$

Copyright

๑ 2019 by Wroclaw Medical University

This is an article distributed under the terms of the

Creative Commons Attribution 3.0 Unported License (CC BY 3.0)

(https://creativecommons.org/licenses/by/3.0/)

\begin{abstract}
A lack of knowledge about biopsy techniques and the management of biopsy specimens can cause artifacts. Artifacts are false structures that change the normal morphological and cytological features of tissues. This review article aimed to familiarize clinicians / dentists / surgeons with the factors causing artifacts and with the efficient strategies to prevent or minimize their occurrence. Non-adherence to several rules can result in the formation of artifacts. The clinician's performance during and after the surgical procedure (until the sample is received by the laboratory) may damage the biopsy specimen or make it susceptible to damage. Artifacts may not be clinically considered noteworthy. However, by modifying the histopathological features of the specimen, they can lead to serious errors in the interpretation of lesions. Knowledge on the part of clinicians / dentists / surgeons regarding the factors and potential conditions that can lead to artifacts can decrease the risk of their occurrence, and considerably help pathologists and patients by paving the way for a correct diagnosis, and consequently an appropriate treatment plan.
\end{abstract}

Key words: biopsy, dentist, artifact, oral lesion

Słowa kluczowe: biopsja, dentysta, artefakt, zmiana patologiczna w jamie ustnej 


\section{Introduction}

The detection of oral lesions by dentists is highly important, ${ }^{1,2}$ because in many diseases or conditions, oral lesions manifest themselves sooner than cutaneous lesions. ${ }^{3}$ This can help in an early diagnosis and the subsequent management of the disease in its initial stages. ${ }^{3}$ The clinical diagnosis of lesions is confirmed with different techniques. ${ }^{1}$ The gold standard of diagnostic procedures is biopsy. ${ }^{4-6}$ Biopsy is defined as taking a sample of a living organism, ${ }^{4,5,7}$ which can include the entire lesion or a part of it. ${ }^{5,8}$ Biopsy is performed to allow a histopathological analysis of the specimen under a microscope to make a definite diagnosis., ${ }^{9,10}$ This assessment is important for the diagnosis of the lesion and also to determine the presence/absence of evidence of malignancy. Biopsy provides information about the clinical course of the lesion and may even provide prognostic data. All these can directly affect the patient management. ${ }^{11,12}$

Nonetheless, in some cases, dentists fail to send tissue specimens to histopathological laboratories and explain that they are concerned about the risk of misdiagnosing the lesion. ${ }^{12}$

One challenge in the correct interpretation of histopathological sections is the presence of defects not related to the existing disease. ${ }^{13,14}$ In microscopic analysis, such defects can create manifestations that are not necessarily related to the actual histological/histopathological features of the specimen. ${ }^{13}$ These defects are known as artifacts. ${ }^{13}$ The term 'artifact' is derived from 2 Latin terms: 'ars' and 'factum,' and is defined as a false or altered tissue structure in a microscopic feature as a result of some external factors. ${ }^{5}$ Artifacts are illusive structures, although they can be misinterpreted as real ones. ${ }^{13}$ Artifacts can interfere with the histopathological assessment of the specimen ${ }^{6}$ and affect the pathologist's ability to correctly diagnose lesions, especially in small samples. ${ }^{12}$ They also compromise the correct histopathological interpretation of specimens, especially at the margins. ${ }^{15}$

Biopsy is a simple, minor surgical procedure. ${ }^{16,17}$ However, achieving an accurate and correct diagnosis requires more than just a correct surgical technique. ${ }^{18,19}$ Suitable tissue preparation for microscopic analysis depends on the correct performance of the dentist/surgeon, assistant and lab staff to minimize the risk of artifact occurrence. ${ }^{19}$

Biopsy (taking a tissue sample) comprises 6 steps: selection of the biopsy site, preparation of the surgical field, anesthetic injection, incision, handling of the biopsy sample, and suturing of the surgical wound. ${ }^{20}$ The processing of the tissue sample is a long process, from surgical removal to staining and mounting the tissue sections on the slides. Artifacts may occur at any step, from the time of performing biopsy to the final step of mounting. ${ }^{13}$ It is imperative for clinicians / dentists / surgeons to have adequate knowledge about artifacts ${ }^{5}$ and this study is aimed to familiarize them with tissue artifacts. This review article discusses the causes of artifacts during surgery, the fixation and transfer of the samples to the lab in order to find strategies to minimize their occurrence.

\section{Preoperative surgical artifacts}

Artifacts can change the normal morphological and cytological appearance of the biopsied samples., ${ }^{5,21}$ They may be confined to only a small portion of the sample. As such, they can be easily detected by an experienced pathologist and no longer interfere with an accurate pathology report and a correct diagnosis. ${ }^{5}$ However, in some cases, the artifactual damage may be extensive or involve the entire sample. Then, artifacts result in a suboptimal quality or quantity of the sample for diagnosis or may even render the tissue useless. ${ }^{21}$

\section{Artifacts caused by the surface preparation of the surgical field prior to biopsy}

After the biopsy site has been precisely selected, ${ }^{1}$ the preparation of the site with iodine tincture or other colored solutions should be avoided.,22 Colored antiseptics or similar agents are not recommended for disinfecting the surface or the external margins of the incision site ${ }^{6}$ since they can interfere with tissue processing and staining procedures. If they are nevertheless used, dentists must inform the lab about it. ${ }^{21}$ It should be noted that toluidine blue, used to determine the most representative part of premalignant and malignant oral lesions, ${ }^{3,23}$ does not interfere with the aforementioned processes. ${ }^{6}$

\section{Artifacts caused by injection}

Injecting the anesthetic solution into the biopsy site can damage the tissue sample $e^{4,8}$ and cause 2 major tissue changes $^{24}$ :

- bleeding and extravasation of red blood cells due to needle insertion into the tissue, and the subsequent possible masking of tissue structures ${ }^{7,24,25}$;

- splitting of connective tissue bands, associated with vacuolization. ${ }^{20,24}$

In a microscopic feature, the area into which the anesthetic agent has been directly injected shows artifactual tissue edema or distortion, which can lead to misdiagnosis. For instance, the formation of a bulla or artifactual edema in the gingival tissue may mistakenly lead to the diagnosis of Crohn's disease or orofacial granulomatosis. ${ }^{26}$

Block injection is recommended to prevent artifacts. If not possible, ${ }^{3}$ the site of infiltration anesthesia injection should be adequately far from the lesion. ${ }^{25}$ Injection should be administered at a distance of at least 3-4 $\mathrm{mm}$ from the lesion and at 4 points around it (superior, inferior, right, and left). ${ }^{3}$

Excessive pressure should be avoided ${ }^{7}$ and the anesthetic solution should be injected slowly. ${ }^{19}$

If achieving hemostasis is among the objectives of injection, it should be administered deeply into the lesion or postponed to immediately after the biopsy. ${ }^{25}$ 


\section{Artifacts during surgery}

\section{Artifacts due to the use of biopsy instruments}

Some cutting instruments, such as a scalpel, forceps, a punch, electrode blades/electroscalpels, and laser blades, are used to take biopsy samples. ${ }^{7,15,27}$

Scalpel

Biopsy samples are usually obtained using surgical scalpels. ${ }^{3,11}$ This is considered a conventional method of biopsy. ${ }^{11,28}$ It seems that an incision with a sharp scalpel causes less tissue damage. ${ }^{8,14}$ Sharp instruments are required for biopsy. ${ }^{3}$ The sample should be taken with one sharp incision. ${ }^{7}$ Multiple incisions with a blunt scalpel $^{5,8,22,28}$ can cause a number of artifacts in the sample. ${ }^{28}$ A blunt scalpel can cause squeeze artifacts, ${ }^{22}$ which are a form of tissue distortion that may result from even the slightest compression of the tissue. ${ }^{5,20}$ These artifacts include crush, hemorrhage, split, fragmentation, ${ }^{5,20}$ or the occurrence of pseudocysts in the tissue (Fig. 1A-E). ${ }^{20,22}$

The split artifact can occur at the surface or margins of the samples taken with a scalpel (especially a blunt scalpel). ${ }^{5,28}$ Several incisions made with a scalpel result in a split between the epithelium and the connective tissue (Fig. 1F). 5,28 The split artifact creates a false impression of vesiculobullous lesions. ${ }^{5,28}$ The crush artifact is destructive and dangerous, ${ }^{24}$ and can occur even at the slightest compression of the tissue. ${ }^{5}$ It changes the morphology of the tissue and squeezes chromatin out of the nucleus. ${ }^{24}$ Microscopically, crushed cells appear as black chromatin strands, which may be mistaken for a dysplastic lesion. ${ }^{5}$ Inflammatory and tumor cells are most susceptible to the crush artifact (Fig. 2A-C). ${ }^{24}$

\section{Forceps}

They also can be used to perform biopsy. ${ }^{7,29}$ They facilitate the biopsy of oral soft tissues and small salivary glands. Forceps have 2 cusps and a window that allows the compaction of the target tissue between them. ${ }^{7}$ The use of dentate forceps is an old technique. They firmly hold the tissue and acceptably protect it during removal. ${ }^{26}$ If used inappropriately, forceps can also cause squeeze artifacts, just like blunt scalpels., ${ }^{5,22}$ Forceps should never grasp the lesion, ${ }^{25}$ because it can result in the crush artifact. ${ }^{4,8}$ Dentate forceps can create holes in the tissue when used carelessly with great force. ${ }^{3,16}$ Such holes can histologically mimic mucosal pits or an epidermoid cyst. ${ }^{16}$ An inappropriate use of forceps can also result in the formation of pseudocysts in the tissue. ${ }^{5,16,24,25}$ The teeth of forceps can push the superficial epithelium into the underlying connective tissue. This, along with the compression of the connective tissue, can create pseudocysts. ${ }^{5,24,25}$
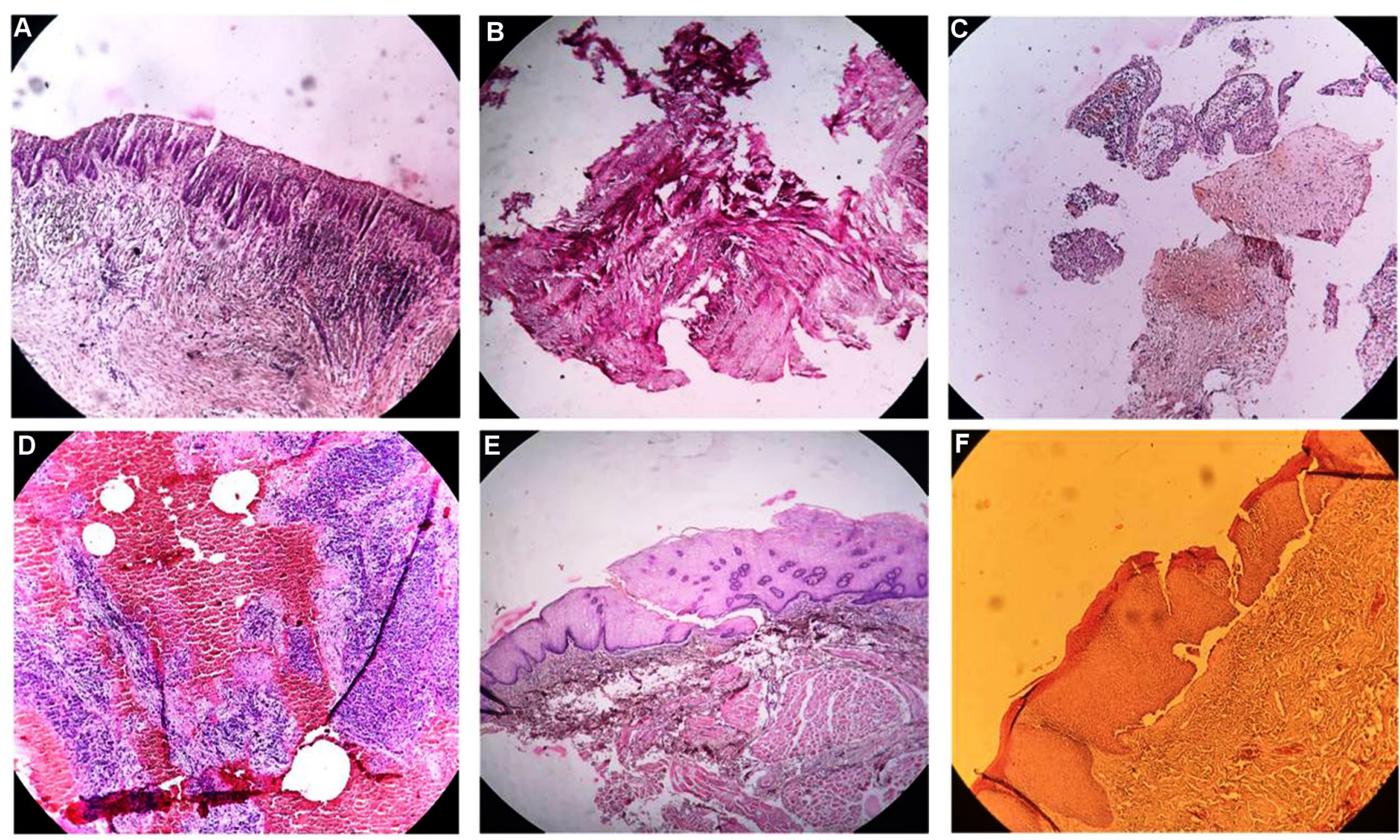

Fig. 1. A - epithelial tissue crush artifact; B - connective tissue crush artifact; C - fragmentation of the tissue sample; D - hemorrhage artifact; E - split artifact; $\mathrm{F}$ - split between the epithelial and connective tissues, false impression of a vesiculobullous lesion

Hematoxylin and eosin staining $(\mathrm{H} \& \mathrm{E}), \times 100$ original magnification. 

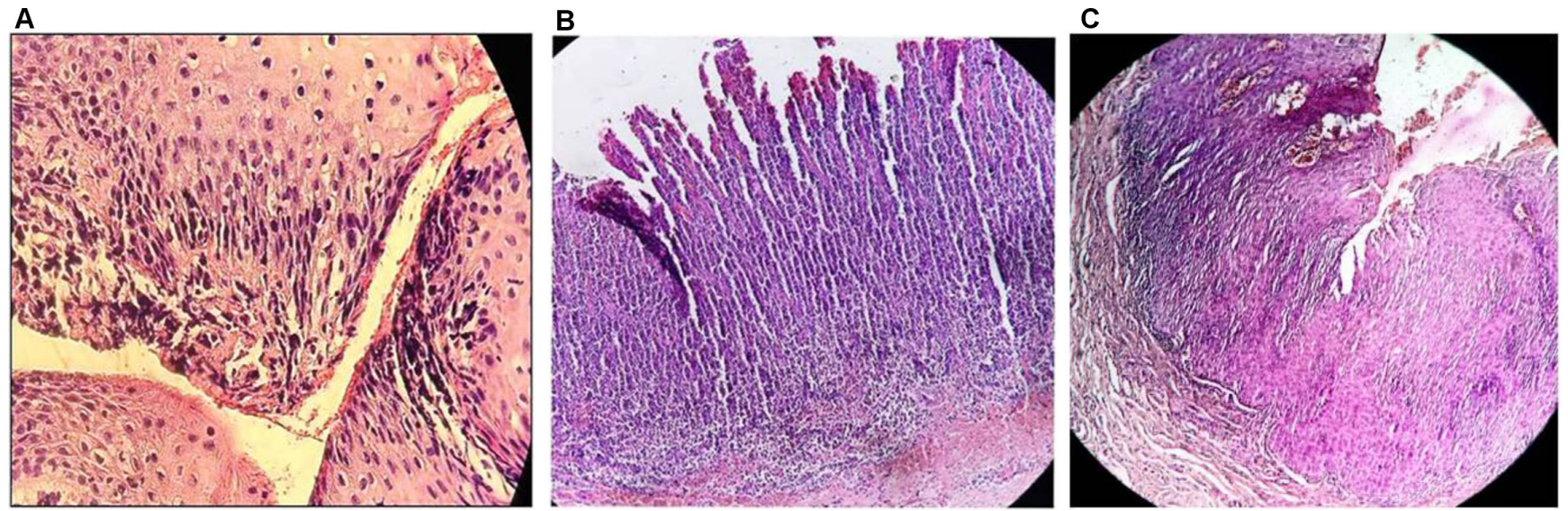

Fig. 2. A - crushed cells that microsopically mimic dysplastic features ( $H \& E ; \times 400$ original magnification); $B-$ crush artifact of inflammatory cells (H \& E; $\times 100$ original magnification); $C$ - crush artifact of tumor cells ( $H \& E_{;} \times 100$ original magnification)

These psedocysts, which apparently line with the surface epithelium, can make the exact assessmment of the sample difficult. ${ }^{5,24,25}$ When the teeth of forceps perforate the tissue, they not only create voids or tears, but also compress the surrounding tissue. ${ }^{19,25}$ Microscopically, the tissue appears distorted with scalloped serrations (caused by the forceps tip) and crushed cells (Fig. 3A-C). ${ }^{5,25}$ The compression of the tissue eliminates its cytological details. It also changes the dimensions of the nucleus, and particularly its ratio to the cytoplasm. ${ }^{24,25}$ These changes may be sufficient to complicate diagnosis ${ }^{16}$ or lead to misdiagnosis. ${ }^{25}$ Forceps artifacts can be overcome by the correct handling and careful use of this instrument. ${ }^{5}$

The lesion should not be directly grasped with forceps $^{25}$; the grasped tissue should be acceptably far from the biopsy site. ${ }^{26,29}$ Blunt forceps should be used instead of toothed forceps. ${ }^{13,24}$

Excessive force at the time of grasping should be avoided in order to prevent significant changes in the epithelium and the underlying connective tissue. ${ }^{25}$

Suturing should be performed at the sample border and used instead of forceps for tissue immobilization. ${ }^{24}$

\section{Punch}

The use of a punch is an affordable, fast, simple, and safe technique for biopsy. ${ }^{7}$ Evidence shows that it creates fewer artifacts in the tissue compared to a scalpel. ${ }^{13,15}$ In punch biopsy, artifacts are in the form of tissue fragmentation, probably due to the use of scissors for separating the sample from the underlying tissue base. ${ }^{13}$ It cannot be used for deep lesions and punch biopsy is limited to the epithelial or superficial mesenchymal tissues. ${ }^{7}$ The use of a punch in some areas, such as the soft palate, maxillary tuberosity or floor of the mouth, is difficult due to the mobility of the site and the absence of a hard, fixed tissue. ${ }^{3,7}$ The punch biopsy of freely mobile tissues ${ }^{3}$ can damage the tissue and cause artifacts..$^{3,7}$
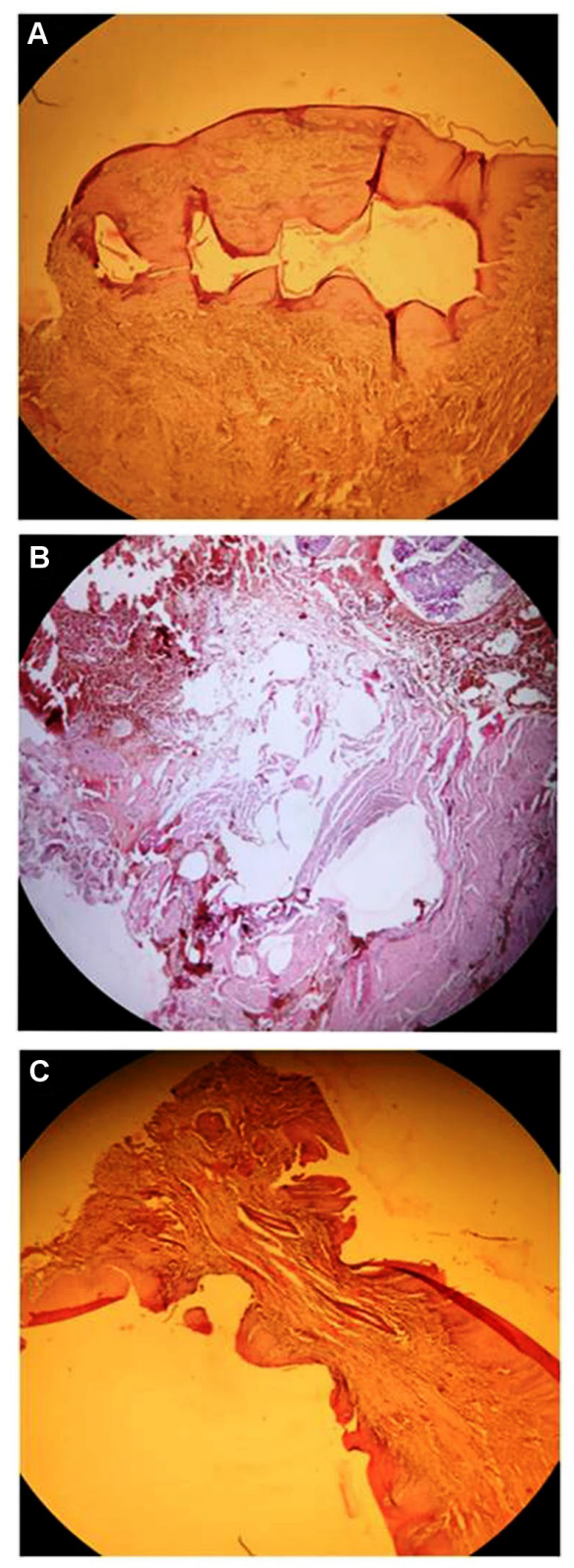

Fig. 3. Artifacts due to forceps

A - pseudocyst; $B$ - tearing of the connective tissue; $C$ - compression of the tissue samples; $H \& E ; \times 100$ original magnification. 


\section{Electrical cautery instruments and laser}

The surgical electrical cautery instruments and laser have the advantage of causing hemostasis during surgery. ${ }^{3}$ On the other hand, overheating generated by these devices can cause changes in the epithelial and connective tissues (the fulguration artifact). ${ }^{5,21,30}$ In the tissue sections with the fulguration artifact, epithelial cells appear detached. ${ }^{24,25}$ The nuclei of cells have a spindled, palisading shape ${ }^{24,25}$ and are hyperchromatic. ${ }^{3}$ These changes can mimic the presence of epithelial dysplasia and lead to an incorrect histopathology report of the lesion, especially at the margins, which are extremely important for the clinician in terms of presence/absence of dysplasia and invasion. ${ }^{28}$ In the fulguration artifact, the separation of the epithelium from the basement membrane can be observed, ${ }^{24,25}$ which may be associated with epithelial loss. ${ }^{28}$ The underlying tissues, such as the fibrous connective tissue, fat and muscle tissues, have an opaque amorphous appearance. ${ }^{24,25,30}$ Protein is deposited when the generated heat results in the boiling of the tissue fluids. ${ }^{24}$ Microscopically, such a tissue has a coagulated and torn appearance. ${ }^{24}$ In the lesion, particularly along the surgical margins, tissue protein coagulation in the form of a wide, extensive basophilic coagulum band is seen, giving an amorphous appearance to the epithelium and the connective tissue (Fig. $4 \mathrm{~A}-\mathrm{C}$ ) ${ }^{20}$

To prevent this, it has been recommended that these instruments should be used according to the dysplastic potential of the lesion. ${ }^{31}$ For lesions suspected of dysplasia or neoplasia, their use should be avoided or the incision margin should be sufficiently far from the interface of the lesion and the normal tissue. ${ }^{7,24,25,27}$

The use of a laser should be limited to excisional biopsy and relatively large samples, where an adequate margin is available. ${ }^{3,28}$

Low power settings of the laser should be used to effectively decrease the risk of separating the epithelium from the basement membrane and of epithelial loss during tissue processing. ${ }^{28}$

A combination of electrosurgery and scalpel should be used instead of electrosurgery alone, because the former would yield more favorable results. In this technique, a scalpel is used for the primary incision around or within the lesion, and then the lesion is completely excised using electrosurgery. This method results in optimal hemostasis and minimizes the heat exposure of the sample., ${ }^{7,24}$

Cutting electrodes should be used for tissue sampling rather than coagulation electrodes. ${ }^{19,24}$ This is conventionally done by using low-milliampere current. ${ }^{5,20,24,25}$

The intentional or incidental contact of the tip of the cutting electrode with metal instruments used for holding the sample should be prevented, because it can cause tissue changes. ${ }^{24,25}$
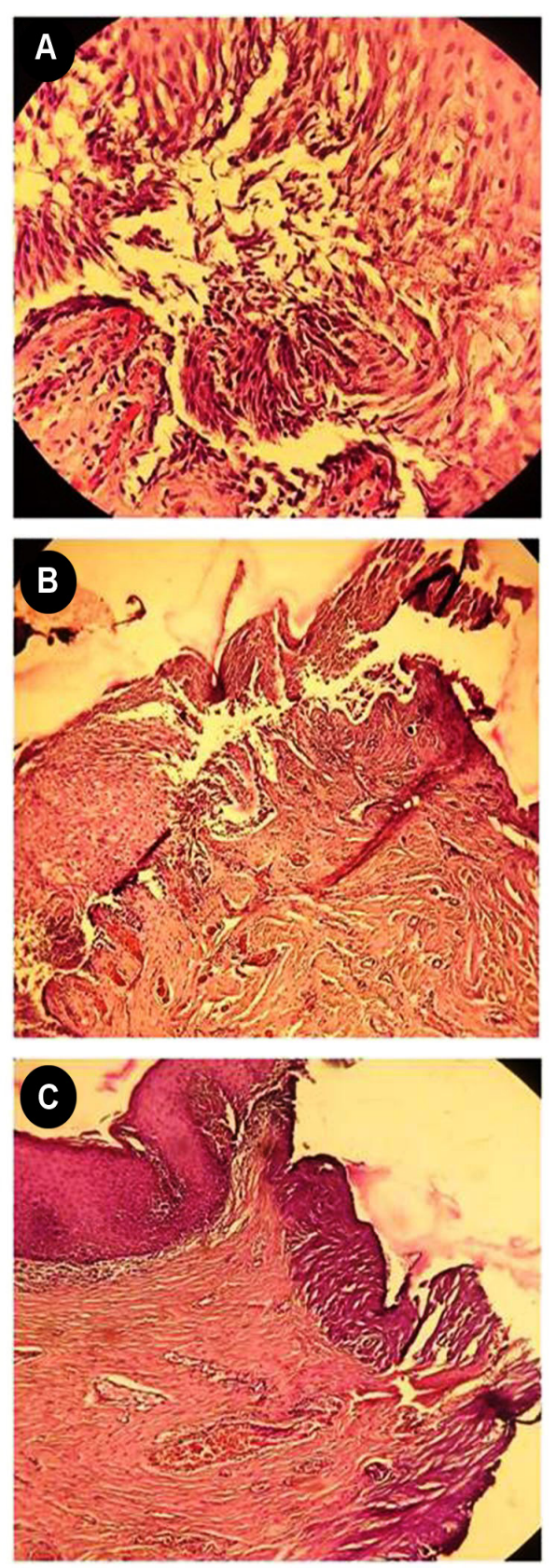

Fig. 4. Fulguration artifact

A - detached epithelium ( $H$ \& E; $\times 400$ original magnification); $B$ - separation of the epithelium from the baseline membrane ( $\mathrm{H} \& \mathrm{E} ; \times 100$ original magnification); C - extensive basophilic coagulum band along the surgical margin ( $H \& E_{;} \times 100$ original magnification).

\section{Artifacts due to the improper handling of the tissue specimens}

Care must be taken when handling mucosal biopsy samples, since the tissue specimen can be easily damaged. The presence of artifacts in the histopathological sections of damaged tissue can decrease their diagnostic accuracy or render them useless. ${ }^{26}$ Traumatic injuries and rough handling can cause artifacts in the specimen. ${ }^{3,26} \mathrm{Su}$ turing is one common method to limit them. It enables the traction and elevation of the tissue during biopsy. ${ }^{26}$ 
Moreover, it prevents the unwanted movement of the tissue (especially mobile structures, such as the tongue) during the procedure. ${ }^{26,29}$ They orientate at least one side of the lesion, facilitate the surgical procedure, and prevent the compression and destruction of the tissue specimen. ${ }^{7}$ However, care must be taken, since the excessive traction of the tissue can cause the laceration or crushing of the specimen, and significantly damage the epithelium or connective tissue. ${ }^{7}$ It can also split the epithelium from the connective tissue and mimic the appearance of vesiculobullous lesions. ${ }^{5}$ The forced traction of the surface epithelium against the underlying connective tissue can cause pseudocysts, and result in the loss of cytoplasmic and nuclear features. ${ }^{21}$ The excessive traction can cause tissue fragmentation ${ }^{28}$ and the subsequent bleeding can be interpreted as a pathologic change by an inexperienced pathologist. ${ }^{13}$

Thus, it is important:

- to handle the tissue specimen with care ${ }^{21,29}$;

- not to apply too much pressure during tissue traction with the sutures ${ }^{5}$;

- to ensure that the sutures have not been placed within the area designated for biopsy;

- to ensure that the suture knots are loose, since firm knots can cause tissue crush ${ }^{26}$ (inflammatory cells ${ }^{28}$ and tumor cells are susceptible to crush artifacts, which can make the specimen uninterpretable). ${ }^{24}$

\section{Vacuum artifact}

This type of artifact is caused by vacuuming the tissues, ${ }^{4}$ especially the connective tissue around odontogenic cysts and dental follicles, with surgical suction tips. These artifacts are seen as large and mostly pleomorphic vacuoles in the connective tissue, similar to the traumatized fat tissue. ${ }^{19}$

\section{Artifacts due to the contamination of the specimens}

Some artifacts are due to the contamination of the specimen with foreign bodies, which may occur during surgery. ${ }^{21,30}$ Cotton and starch are among the most common contaminants. ${ }^{20}$ Starch artifacts may occur due to the contamination of the specimen with starch powder, which is used as a lubricant in surgical gloves. ${ }^{5,20,21}$ Starch granules may be superficially similar to atypical epithelial cells, ${ }^{5,20}$ and mimic the appearance of salivary gland diseases, autoimmune disorders, granulomatous lesions, or benign epithelial lesions. ${ }^{5}$ These spore-like structures with a dark central area could be mistaken as pyknotic nuclei or mitotic nuclei. ${ }^{20,21}$ Starch granules appear light blue on hematoxylin and eosin staining ( $\mathrm{H} \& \mathrm{E})$, blueblack with Lugol's solution and deep lilac-red on periodic acid-Schiff staining (PAS). ${ }^{5,20}$ The starch artifact can be prevented by using latex gloves. ${ }^{5}$ The presence of cotton in the histopathological sections (cotton contamination) may resemble eosinophilic, amyloid-like or black substances. ${ }^{5,20}$ The similarity of cotton to an amyloid-like material, which is among the characteristics of odontogenic tumors, may result in misdiagnosis. ${ }^{5}$

To control bleeding during surgery, gel foam or surgical sponges are used. ${ }^{13}$ In the histopathological sections contaminated with gel foam, the characteristic appearance of distorted superficial spaces is seen. These spaces may be filled with blood and surrounded by slightly basophilic gelatin walls. ${ }^{13}$ Dentists/surgeons should be careful to prevent the foreign body contamination of the specimens. ${ }^{19}$ On the other hand, knowledge about these materials and their correct identification in the sections can help in establishing an accurate pathologic interpretation. ${ }^{5}$

\section{Post-surgical artifacts (occurring after specimen removal until a transfer to the lab)}

\section{Artifacts due to a delay in fixation}

After tissue removal, the biopsy specimen should be fixed. ${ }^{5,7,17}$ Autolysis and bacterial attack start immediately after tissue removal. ${ }^{19,32}$ Fixation stops these changes. ${ }^{19,32,33}$ It maintains the integrity of cells and their chemical components, ${ }^{34}$ preserving the tissue in conditions like when alive. ${ }^{13,34}$ The time interval between the surgical removal of the sample and its immersion in a proper fixative is referred to as the ischemia or hypoxia time, ${ }^{34,35}$ which is associated with the activation of tissue enzymes, autolysis, and the degradation of proteins, DNA and RNA. ${ }^{34}$ A delay in fixation yields a poor histopathologic feature. $^{5}$ It also changes the quality of cell staining ${ }^{24,25}$ and makes mitosis hard to detect. ${ }^{5}$ Cells shrink and cytoplasmic clumping is observed. ${ }^{7,25}$ Chromatin in the nuclei cannot be detected and the nucleoli are not visible in some cases. ${ }^{5,7}$ Some changes occur in tissue structures as well. ${ }^{5,7,25}$ Vascular, nervous and gland structures lose their details, ${ }^{5,7,25}$ simulating scar tissue formation ${ }^{25}$ or the loss of cellularity. ${ }^{5,7,25}$ To prevent the occurrence of these changes, the biopsy samples should be placed in a suitable fixative immediately after removal. ${ }^{19,36}$

\section{Artifacts due to the type of fixative used}

The $10 \%$ neutral buffered formalin is an alternative fixative to optimize the fixation of the biopsy specimen for the routine histopathological assessment. ${ }^{12,24,36} \mathrm{De}$ spite attempts to find a replacement for it, ${ }^{35,37}$ formalin remains the most popular, reliable and affordable fixation solution. ${ }^{34}$

Tap water, ${ }^{3}$ distilled water or saline are occasionally used for tissue fixation. ${ }^{18,20,33}$ Tissues fixed with these solutions often show abnormal cellular or structural 
changes $^{33}$ that can pose a challenge for the correct diagnosis of the lesion. ${ }^{33}$ Saline does not cause any fixation at all ${ }^{19}$ and should not be used even for a short time. ${ }^{33}$ The immersion of the specimen in saline causes the bizarre appearance of epithelial cells, which can suggest malignancy. ${ }^{5}$ Antiseptics, mouthwashes or local anesthetic solutions are also inappropriate for tissue fixation. ${ }^{3,5,15,26}$ The specimen cannot be properly fixed with these solutions, ${ }^{3,5,15,26}$ and thus, tissue autolysis continues. ${ }^{24}$ Fixatives that are protein precipitants, such as ethanol and methanol (irrespective of their osmotic pressure), cause tissue shrinkage. Thus, tissues that are attached to each other when alive may be pulled apart in these fixatives and leave empty spaces. ${ }^{5}$ Alcohol makes the tissue fragile and creates artifacts following microtome sectioning (chattering and the Venetian blind artifact). ${ }^{24}$ The use of ethanol as a fixative can cause the crush artifact, which is due to protein coagulation seen as intense eosinophilic staining at the center of the tissue specimen in $\mathrm{H} \& \mathrm{E}$. Ethanol does not completely fix proteins. ${ }^{5}$ The use of alcohol as a fixative results in the weak staining of the epithelium and an inadequate fixation of the connective tissue. In such conditions, collagen bundles have an amorphous feature, which is not due to scar tissue formation; it is an artifact. ${ }^{24}$ When encountering the tissue specimen in an unsuitable fixative, it should be immediately replaced with the $10 \%$ neutral buffered formalin ${ }^{5}$ to prevent further morphological changes in the tissue. ${ }^{20}$

Freezing the specimen before or instead of fixation is not suitable..$^{4,5,7,25,37}$ It can cause the dehydration of cells and the subsequent condensation of the cytoplasm. 5,7,24 This change is characterized by the granular paranuclear condensation of the cytoplasm. ${ }^{24}$ The formation of ice crystals following the freezing of the tissue specimen results in the formation of interstitial and intracytoplasmic vacuoles. ${ }^{5,7,24}$ In the histopathologic sections of the frozen tissues, gaps in the tissue cause the appearance of Swiss cheese holes in the epithelium, indicative of areas where ice crystals have perforated the tissue. ${ }^{24}$

\section{Artifacts caused by formalin}

The $10 \%$ neutral buffered formalin is the best tissue fixative introduced so far. ${ }^{5,24}$ Fixation with formalin prevents autolysis and the occurrence of some artifacts. ${ }^{19}$ However, some considerations should be taken into account when using it. Formalin itself can cause tissue artifacts. . $7,19,34^{-}$

The concentration of formalin should be adequate to ensure accurate fixation. ${ }^{7}$ Formalin is a diluted solution of buffered formaldehyde. ${ }^{6}$ However, sometimes the ancillary staff may overdilute it. ${ }^{3}$ This can result in the weak fixation of the tissue specimen. ${ }^{3}$ Artifactual changes occur in the form of the acantholysis of epithelial cells, whereas the basal cell layer remains attached to the underlying connective tissue. This acantholytic artifact can mimic pemphigus, as well as Hailey-Hailey disease or Darier's disease. ${ }^{24}$
To ideally preserve the morphological details of the tissue, fixation should be done at room temperature. Although a rise of temperature $\left(45-55^{\circ} \mathrm{C}\right)^{13,20}$ increases the rate of fixation, the overheating of formalin can cause vacuolization, the overstaining of cytoplasm and the appearance of pyknotic nuclei. ${ }^{13}$

The tissue specimen fixed in the $10 \%$ neutral buffered formalin should be sent to the lab as soon as possible. ${ }^{7}$ Formalin fixation is often associated with color change, ${ }^{3}$ volume change (33\% shrinkage $)^{19,24}$ and the hardening of the tissue. ${ }^{3,25}$ Moreover, secondary shrinkage may occur in the specimen following long-term immersion in formalin. ${ }^{5,24}$ Similar to delayed or inadequate fixation, long-term fixation also causes some changes in the tissues. ${ }^{19,25}$ Long-term formalin fixation can cause secondary shrinkage and hardening. ${ }^{5}$ This can result in tissue separation, microscopically mimicking empty spaces. ${ }^{5}$

Formalin fixation can cause the pigmentation artifact. The bonding of formalin with the heme of red blood cells forms the formalin-heme complex, which is seen as black precipitates in the tissue specimen. ${ }^{5,20,21}$ The fast transfer of the formalin-fixed specimen to the pathology lab enables the lab staff to start tissue processing in optimal fixation conditions. ${ }^{38}$

The preservation of the specimen depends both on the pathologist and on the dentist. Unfortunately, it seems dentists believe that the lab would start processing on their specimen immediately after receipt; however, that is not really the case. ${ }^{39}$

\section{Artifacts due to the size of the specimen}

The ability of oral pathologists to correctly interpret the biopsy sample depends not only on the quality, but also on the quantity of the sample. ${ }^{20,30}$ In biopsy, and more commonly in incisional biopsy, if the specimen is thin, especially if it is in the form of a thin, delicate oral mucosa ribbon, ${ }^{5}$ its shrinkage in formalin causes the curling and bending of the tissue. ${ }^{5,30}$ This change, known as the curling artifact, complicates the orientation of the specimen. ${ }^{5,20,30}$ Unsuitable orientation can lead to the tangential incisions of the specimen, or the sectioning of only the epithelium or the connective tissue, and not both. ${ }^{3}$

Moreover, the curling of the specimen onto itself during fixation often results in the loss of junction between the epithelium and the connective tissue, especially if the specimen does not have the submucosal layer or the underlying muscle. ${ }^{7}$

This artifact can be prevented by ensuring an adequate depth of the specimen. ${ }^{5}$

If the biopsy sample is small, thin and narrow, the specimen should be immediately placed on a piece of stiff, ${ }^{3,24}$ sterile/clean paper $^{1,3}$ for a short time (i.e., $\left.1 \mathrm{~min}\right)^{4,15,22}$ before its immersion in a fixative so that its surface faces upward $^{3}$ and its connective tissue side faces downward..$^{15}$ By doing so, the epithelium is preserved in its correct 
position, ${ }^{24}$ and one can ensure that the tissue specimen is positioned straight during fixation and is well-oriented for the histopathological assessment. ${ }^{15}$

Surgeons can use sutures to help in the correct orientation of the specimen and send a note to the lab regarding the relation between the sutures and the specimen. ${ }^{3}$

\section{Conclusions}

Knowledge on the part of clinicians / dentists / surgeons regarding the factors and potential conditions that can lead to artifacts can decrease the risk of their occurrence, and considerably help pathologists and patients by paving the way for a correct diagnosis, and consequently an appropriate treatment plan.

\section{ORCID iDs}

Massoumeh Zargaran (D) https://orcid.org/0000-0002-8843-2590

\section{References}

1. López Jornet $P$, Velandrino Nicolás $A$, Martínez Beneyto $Y$, Fernández Soria M. Attitude towards oral biopsy among general dentists in Murcia. Med Oral Patol Oral Cir Bucal. 2007;12(2):E116-E121.

2. James K, Toner M, Stassen LF. Performing mucosal tissue biopsies in general dental practice. J Ir Dent Assoc. 2011;57(4):203-208.

3. Kumaraswamy KL, Vidhya M, Rao PK, Mukunda A. Oral biopsy: Oral pathologist's perspective. J Cancer Res Ther. 2012;8(2):192-198.

4. Avon SL, Klieb HB. Oral soft-tissue biopsy: An overview. J Can Dent Assoc. 2012;78:c75.

5. Rastogi V, Puri N, Arora S, Kaur G, Yadav L, Sharma R. Artefacts: A diagnostic dilemma - a review. J Clin Diagn Res. 2013;7(10):2408-2413.

6. Melrose RJ, Handlers JP, Kerpel S, Summerlin DJ, Tomich CJ; American Academy of Oral and Maxillofacial Pathology. The use of biopsy in dental practice. The position of the American Academy of Oral and Maxillofacial Pathology. Gen Dent. 2007;55(5):457-463,468.

7. Mota-Ramírez A, Silvestre FJ, Simó JM. Oral biopsy in dental practice. Med Oral Patol Oral Cir Bucal. 2007;12(7):E504-E510.

8. Jephcott $A$. The surgical management of the oral soft tissues: 3. Biopsy. Dent Update. 2007;34(10):654-657.

9. Manyam R, Reena K, Saraswathi TR. Role of deeper sections in diagnostic oral histopathology: A retrospective study. Indian J Dent Res. 2011;22(1):62-65.

10. Wan A, Savage NW. Biopsy and diagnostic histopathology in dental practice in Brisbane: Usage patterns and perceptions of usefulness. Aust Dent J. 2010;55(2):162-169.

11. Saini R, Saini S, Sharma S. Oral biopsy: A dental gawk. J Surg Tech Case Rep. 2010;2(2):93.

12. Logan RM, Goss AN. Biopsy of the oral mucosa and use of histopathology services. Aust Dent J. 2010;55(Suppl 1):9-13.

13. Bindhu $P$, Krishnapillai $R$, Thomas $P$, Jayanthi $P$. Facts in artifacts. J Oral Maxillofac Pathol. 2013;17(3):397-401.

14. Allen CM. The oral pathology report: Submission of specimens and interpretation of results. Dermatol Ther. 2002;15(3);179-184.

15. Poh CF, Ng S, Berean KW, Williams PM, Rosin MP, Zhang L. Biopsy and histopathologic diagnosis of oral premalignant and malignant lesions. J Can Dent Assoc. 2008;74(3):283-288.

16. Camacho Alonso $F$, López Jornet $P$, Jiménez Torres MJ, Orduña Domingo A. Analysis of the histopathological artefacts in punch biopsies of the normal oral mucosa. Med Oral Patol Oral Cir Bucal. 2008;13(10):E636-E639.

17. Pippi R. Technical notes about soft tissues biopsies of the oral cavity. Minerva Stomatol. 2006;55(10):551-566.

18. Atanda AT, Raphael S. Role of surgeons in determining outcome of histopathology specimens. Niger J Surg. 2013;19(2):68-72.
19. Jain N. Essentials before sending biopsy specimens: A surgeon's perspective and pathologists concern. J Maxillofac Oral Surg. 2011;10(4):361-364.

20. Kumar K, Shetty DC, Dua M. Biopsy and tissue processing artifacts in oral mucosal tissues. Int J Head Neck Surg. 2012;3(2):92-98.

21. Khan S, Tijare M, Jain M, Desai A. Artifacts in histopathology: A potential cause of misinterpretation. Research \& Reviews: Journal of Dental Sciences. 2014;2(2):23-31.

22. Seoane J, Varela-Centelles PI, Ramírez JR, Cameselle-Teijeiro J, Romero MA. Artefacts in oral incisional biopsies in general dental practice: A pathology audit. Oral Dis. 2004;10(2):113-117.

23. Handlers JP. Diagnosis and management of oral soft-tissue lesions: The use of biopsy, toluidine blue staining, and brush biopsy. J Calif Dent Assoc. 2001;29(8):602-606.

24. Chatterjee S. Artefacts in histopathology. J Oral Maxillofac Pathol. 2014;18(Suppl 1):S111-S116.

25. Margarone JE, Natiella JR, Vaughan CD. Artifacts in oral biopsy specimens. J Oral Maxillofac Surg. 1985;43(3):163-172.

26. Oliver RJ, Sloan P, Pemberton MN. Oral biopsies: Methods and applications. Br Dent J. 2004;196(6):329-333.

27. Christensen GJ. Soft-tissue cutting with laser versus electrosurgery. J Am Dent Assoc. 2008;139(7):981-984.

28. Yanduri S, Pandey G, Kumar VB, Suma S, Madhura MG. Artifacts in oral biopsy specimens: A comparison of scalpel, punch, and laser biopsies. Indian J Oral Health Res. 2016;2(2):100-105.

29. Davari P, Fazel N. Practical pearls for oral procedures. Clin Dermatol. 2016;34(4):440-448

30. Masthan KM, Sankari SL, Babu NA, Rajguru JP. How to help the oral pathologist in making an accurate diagnosis. J Clin Diagn Res. 2013;7(1):181-184.

31. Romeo U, Palaia G, Del Vecchio A, et al. Effects of KTP laser on oral soft tissues. An in vitro study. Lasers Med Sci. 2010;25(4):539-543.

32. Singhal $P$, Singh NN, Sreedhar G, Banerjee S, Batra M, Garg A. Evaluation of histomorphometric changes in tissue architecture in relation to alteration in fixation protocol - an in vitro study. J Clin Diagn Res. 2016;10(8):ZC28-ZC32.

33. Sengupta S, Prabhat K, Gupta V, Vij H, Vij R, Sharma V. Artefacts produced by normal saline when used as a holding solution for biopsy tissues in transit. J Maxillofac Oral Surg. 2014;13(2):148-151.

34. Comănescu M, Arsene D, Ardeleanu C, Bussolati G. The mandate for a proper preservation in histopathological tissues. Rom J Morphol Embryol. 2012;53(2):233-242.

35. Comanescu M, Annaratone L, D'Armento G, Cardos G, Sapino A, Bussolati $G$. Critical steps in tissue processing in histopathology. Recent Pat DNA Gene Seq. 2012;6(1):22-32.

36. Sleiman R, Kurban M, Abbas O. Maximizing diagnostic outcomes of skin biopsy specimens. Int J Dermatol. 2013;52(1):72-78.

37. Patil S, Rao RS, Agarwal A, Raj AT. Instant transport media for biopsied soft tissue specimens: A comparative study. Scientifica (Cairo). 2015;2015:876531.

38. Start RD, Cross SS, Smith JH. Assessment of specimen fixation in a surgical pathology service. J Clin Pathol. 1992;45(6):546-547.

39. Dimenstein IB. Grossing biopsies: An introduction to general principles and techniques. Ann Diagn Pathol. 2009;13(2):106-113. 